\title{
Estímulo ao aleitamento materno em recém nascido muito baixo peso em uma unidade de neonatologia de um hospital público do estado de São Paulo: Relato de experiência
} Eixo temático: Gestão em Saúde

INTRODUÇÃO: O processo de amamentação é de extrema importância para a saúde e a qualidade de vida dos recém-nascidos (RN) prematuros. Oferece condições vitais ao bebê e vantagens para todos envolvidos neste prática. Nos deparamos ainda no Brasil com taxas de aleitamento materno exclusivo distantes do recomendado pela Organização Mundial da Saúde. Esse cenário é ainda mais dramático quando se refere a RNs prematuros. Espera-se com esta experiência, superar algumas barreiras como a realidade clínica do RN, a separação do binômio durante a internação da criança, falta de experiência da mãe, intercorrências com a mama, além de interferências sociais externas.

OBJETIVO: Demonstrar com iniciativas de gestão assistencial o processo de estímulo ao aleitamento materno em RNs muito baixo peso.

MÉTODOS: Para sustentação da prática proposta, foi realizada inicialmente uma revisão integrativa, posteriormente a coleta de dados, observando a fundamentação, com trabalhos das base de dados: on-line (MEDLINE), (LILACS) e (BDENF) com publicações de 2017 a 2018, com descritores: "Aleitamento Materno" and "Neonatologia" and Assistência em Saúde em Neonatologia and "Recém-nascido" and Enfermagem em Neonatologia" Organizado o planejamento, iniciou-se a coleta de informações e intervenções assistenciais do estímulo a coleta de leite dos bebês da Neonatologia. A primeira estratégia foi estabelecer o Manual do Posto de Coleta de Leite Humano para as mães, com o objetivo de promover, proteger e apoiar a prática da amamentação. Após, entendeu-se a necessidade de gerenciar o volume de leite ordenhado no posto de coleta, o número de ordenhas realizadas, volume de coleta e volume ofertado aos RNs. Identificados os motivos e obstáculos que inibem a coleta de leite materno, foi possível promover estratégias de amparo e incentivo social, afim de diminuir o absenteísmo destas mães e conseqüente maior taxa de aleitamento materno na alta hospitalar.

Figura01: Instrumento de Coleta de Leite Humano

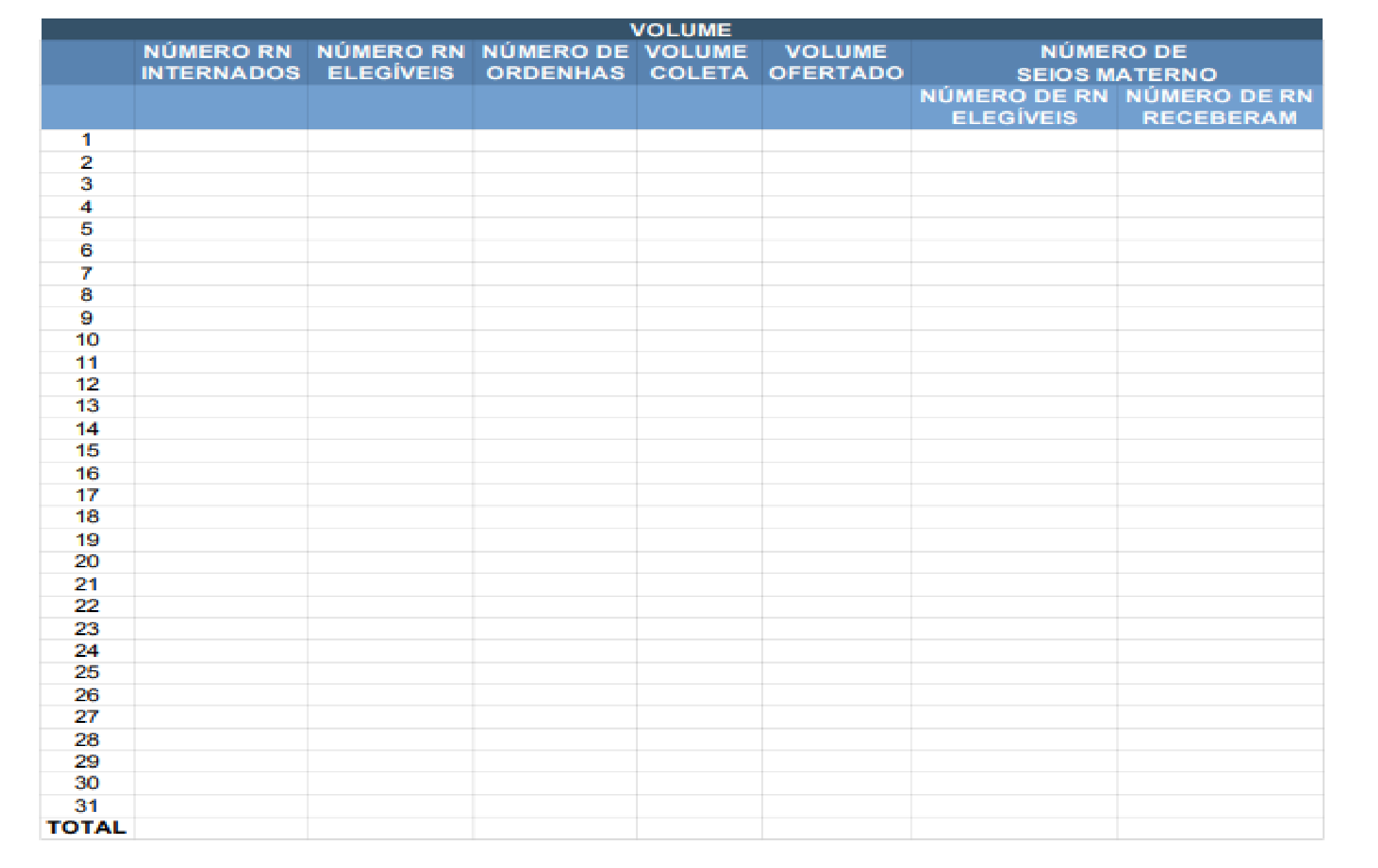

RESULTADOS: Entre os anos de 2015 e 2017 a taxa de leite materno em RN muito baixo peso no momento da alta, definido como oferta de leite materno na forma de aleitamento ou leite materno ordenhado, manteve-se entre 63,6 e $84,6 \%$. Taxa semelhante às encontradas nos $25 \%$ melhores centros da Rede Vermont Oxford.

Figura02: Taxa de aleitamento materno em RNs de extremo baixo peso

\section{Estímulo ao Aleitamento Materno - VDN NETWORK}

Taxa de leite materno no momento da alta

2017: 46.666 recém-nascidos Peso de nascimento: $501 \mathrm{a} 1500 \mathrm{~g}$

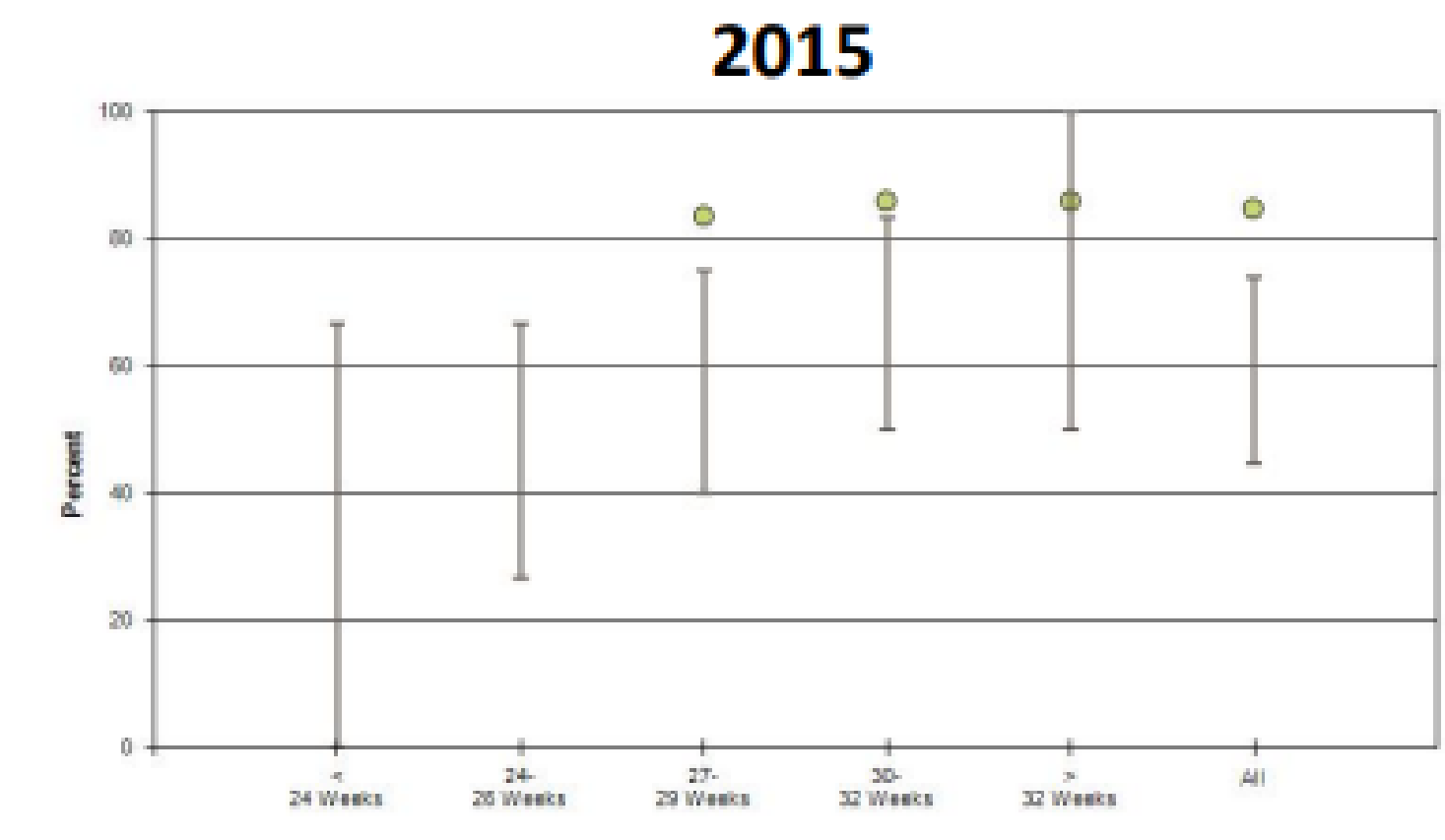

2016

2017
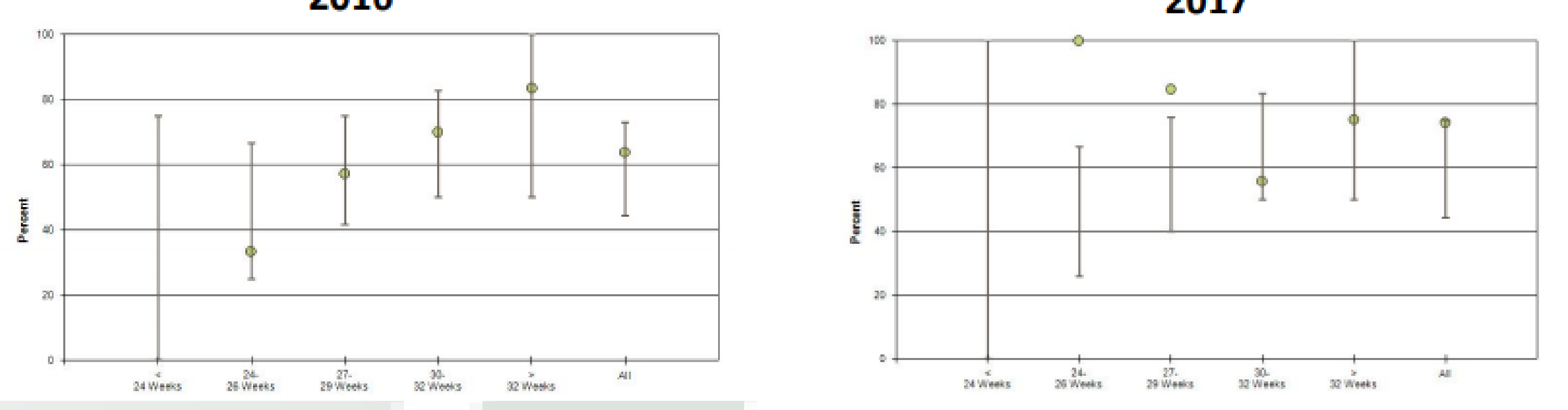

Fonte: Vermont Oxford Network, 2018

CONCLUSÃO: Com o aumento de adesão das mães na conscientização da coleta do leite, progredindo assim para maior oferta aos RNs hospitalizados. Com esta experiência, entendeu-se necessário conhecer os motivos e obstáculos que inibem as mães a adesão da coleta do leite. Com estes motivos identificados, foi possível promover estratégias de amparo e incentivo social, afim de diminuir o absenteísmo destas mães e conseqüente maior oferta de leite e o sucesso exitoso da experiência.

\section{REFERÊNCIAS:}

Silvestre, Patrícia Kelly, Carvalhaes, Maria Antonieta de Barros Leite, Venâncio, Sônia Isoyama, Tonete, Vera Lúcia Pamplona, e Parada, Cristina Maria Garcia de Lima. (2009). Conhecimento e prática da amamentação de profissionais de saúde em serviços públicos de saúde. Revista Latino-Americana de Enfermagem , 17 (6), 953-960. https://dx.doi.org/10.1590/50104-11692009000600005 